\title{
Anatomia da folha das espécies \\ conhecidas de pau-rosa. XI - Chave para identificaçào das espécies
}

\author{
Italo de Vattimo (")
}

\begin{abstract}
Resumo
Neste trabalho, o último de uma série de 11, o autor dá uma chave para identifícação de material de herbário de 10 espécies conhecidas de "pau-rosa" (Aniba Aubl.), baseada em caracteres anatômicos das epidermes superior e inferior das folhas.
\end{abstract}

\section{INTRODUÇÃO}

Concluindo o estudo citomorfológico das epidermes superior e inferior da folha das dez espécies de Aniba Aubl. (Kostermans, 1938), conhecidas até a presente data como pau-rosa ou louro-rosa, importantes fornecedoras de óleos essenciais, o autor apresenta neste último trabalho a chave para identificação de material estéril das mesmas, baseada em caracteres anatômicos das epidermes foliares.

As espécies estudadas (Vattimo, 1968 $a, b, c$ e d, $1969 a, b$ e $c, 1970,1972,1975)$ são as seguintes: Aniba rosaeodora Ducke (conhecida nas Guianas Inglesa e Francesa como pau-rosa-fêmea e no Surină como pau-rosa-verdadeiro), Aniba duckei Kostermans, Aniba parviflora (Meissn.) Mez, Aniba burchellii Kostermans (também denuminada preciosa), Aniba terminalis Ducke, Aniba permollis (Nees) Mez, Aniba mas Kostermans (falso-pau-rosa e pau-rosa-macho no Surinā), Aniba hostmanniana (Nees) Mez, Aniba riparia (Nees) $\mathrm{Mez}$ e Aniba fragrans Ducke (conhecida vulgarmente como macacaporanga).

\section{MATERIAL E MÉTODOS}

O estudo foi realizado na seção de Geobotânica do Jardim Botânico do Rio de Janeiro com folhas de material seco do herbário, identificado por A. J. G. H. Kostermans e A. Ducke e confirmado pela botânica Ida de Vattimo Gil. Foram estudadas folhas dos seguintes espécimens:

\begin{aligned} \multicolumn{1}{c}{ N. } & \multicolumn{1}{c}{ Espécie } \\ 8.357 & A. riparia (Nees) Mez \\ 18.349 & A. fragrans Ducke \\ 18.352 & A. terminalis Ducke \\ 23.980 & A. permollis (Nees) $\mathrm{Mez} \\ 23.981 &$ A. hostmanniana (Nees) $\mathrm{Mez} \\ 24.914 &$ A. duckei Kost. \\ 29.061 & A. parviflora (Meisn) Mez \\ 34.100 & A. rosaeodora Ducke \\ 37.725 & A. burchellii Kost. \\ 37.748 & A. mas Kostermans \end{aligned}

A TÉCNICA EMPREGADA

1 - Corte do terço médio da folha adulta.

2 - Dissociação das epidermes com a mistura de Jeffrey (ácido nítrico e ácido crômico a $10 \%$ em partes iguais).

\section{Coletor}

Determinador

B.A. Krukoff
A. Ducke
A. Ducke
A. Ducke
A. Ducke
A. Ducke
A. Ducke
R. Siqueira
B.A. Krukoff
B.A. Krukoff

B.A. Krukoff

A. Ducke

A. Ducke

B.A. Krukoff

B.A. Krukoff
A.J.G.H. Kostermans
A.J.G.H. Kostermans
A.J.G.H. Kostermans
A.J.G.H. Kostermans
A.J.G.H. Kostermans
A.J.G.H. Kostermans
A.J.G.H. Kostermans
A. Ducke
A.J,G,H. Kostermans
A.J.G.H. Kostermans

3 - Coloração em Sudan IV.

4 - Montagem em xarope de Apathy.

5 - Mensurações das papilas com ocular 15 e objetiva 40 , com o auxílio do disco micrométrico da marca Jena de escala 10:100.

(") - Jardim Botânico do Rio de Janeiro. Bolsista do CNPq. 
6 - $\mathrm{O}$ estudo foi realizado com microscópio monocular Baush \& Lomb.

7 - Fotomicrografias com microscópio Carl Zeiss, oculares $\mathrm{Kpl} 8 \mathrm{X}$ e objetiva Plan 40/063.

8 - Para calcular-se o valor real de cada divisão da escala do disco micrométrico utilizado na ocular, com a objetiva e ocular escolhidas para as mensurações. usou-se: lâmina com escala micrométrica Ernst Leitz, com 200 divisões em $2 \mathrm{~mm}$ e disco micrométrico Jena com escala 10:100.

\section{CHAVE PARA IDENTIFICAÇÃO DE MATERIAL HERBORIZADO (')}

1 - Papilas ausentes na epiderme inferior 2 Papilas presentes na epiderme inferior 4

2 - Pelos ausentes na epiderme inferior; membrana das células em geral reta ou sub-reta em ambas as epidermes (microfotos. 1 e 2) ...... Aniba terminalis Pelos presentes na epiderme inferior; caráter da membrana celular acima referido ocorrendo apenas na epiderme inferior ou em nenhuma ........... 3

3 - Pelos numerosos; membrana das células em geral reta ou sub-reta na epiderme inferior; na epiderme superior ocorrem ao mesmo tempo membranas retas, sub-retas, curvas ou sinuosas, sem predominância de nenhuma das formas citadas (microfotos. 3 e 4) ............... ............... Aniba hostmanniana Pelos escassos; membrana das células em geral levemente sinuosa na epiderme superior (microfotos. 5 e 6 ) ....... ................... Aniba riparia.

4 - Aparelhos estomáticos em geral cobertos por 1 ou 2 papilas das células subsidiárias, na epiderme inferior ....... 5 Aparelhos estomáticos em geral cobertos por 2 a 8 papilas, na epiderme inferior ....................... 6

5 - Membrapa das células da epiderme superior em geral sinuosa a fortemente si- nuosa (microfotos. 7 e 8). Aniba fragrans Membrana das células da epiderme superior reta, sub-reta, curva ou levem nnte sinuosa, ocorrendo ao mesmo tempo essas formas, sem predominância de nenhuma delas (microfotos. 9 e 19) ...... ...................... Aniba mas

6 - Camada de cutina que cobre a face superior e penetra entre as faces laterais verticais das células da epiderme inferior aparece interligando as papilas, devido às divergências de posiçōes das mesmas (vide A. burchellii Kost., Rev. Brasil. Biol. 30 (3) págs. 422/423); (microfoto. 11) ......... Aniba burchellii

Sem essa característica $\ldots \ldots \ldots \ldots 7$

7 - Células da epiderme inferior com papilas delgadas, muito pouco desenvolvidas e com forma regular constante, circular ou elítica. Em geral o diâmetro da forma circular ou o eixo maior da forma elítica é de 3 a $6 \mu$ (microfoto. 12) ........ ................... Aniba duckei

Sem essa característica .......... 8

8 - Membrana das células da epiderme superior em geral reta ou sub-reta (microfotos. 13 e 14) ...... Aniba rosaeodora Sem essa característica .......... 9

9 - Células da epiderme inferior com papilas que podem medir em geral até $15 \mu$. de diâmetro, quando de forma circular ou de eixo maior quando de forma elítica e quando adultas podem apresentar forma irregular. Epiderme superior formada por células de membrana sinuosa (microfotos. 15 e 16) ..... Aniba permollis Células da epiderme inferior com papilas, que em geral não ultrapassam $9 \mu$ de diâmetro, quando de forma circular ou de eixo maior quando de forma elítica, formas estas que são constantes, predominando o tamanho de $6 \mu$. Epiderme superior formada por células de membrana levemente sinuosa (microfotos. 17 e 18) .............. Aniba parviflora.

(1) - A palavra membrana quando citada na chave está se referindo à parte da membrana situada nas faces laterais verticais das células da epiderme. 

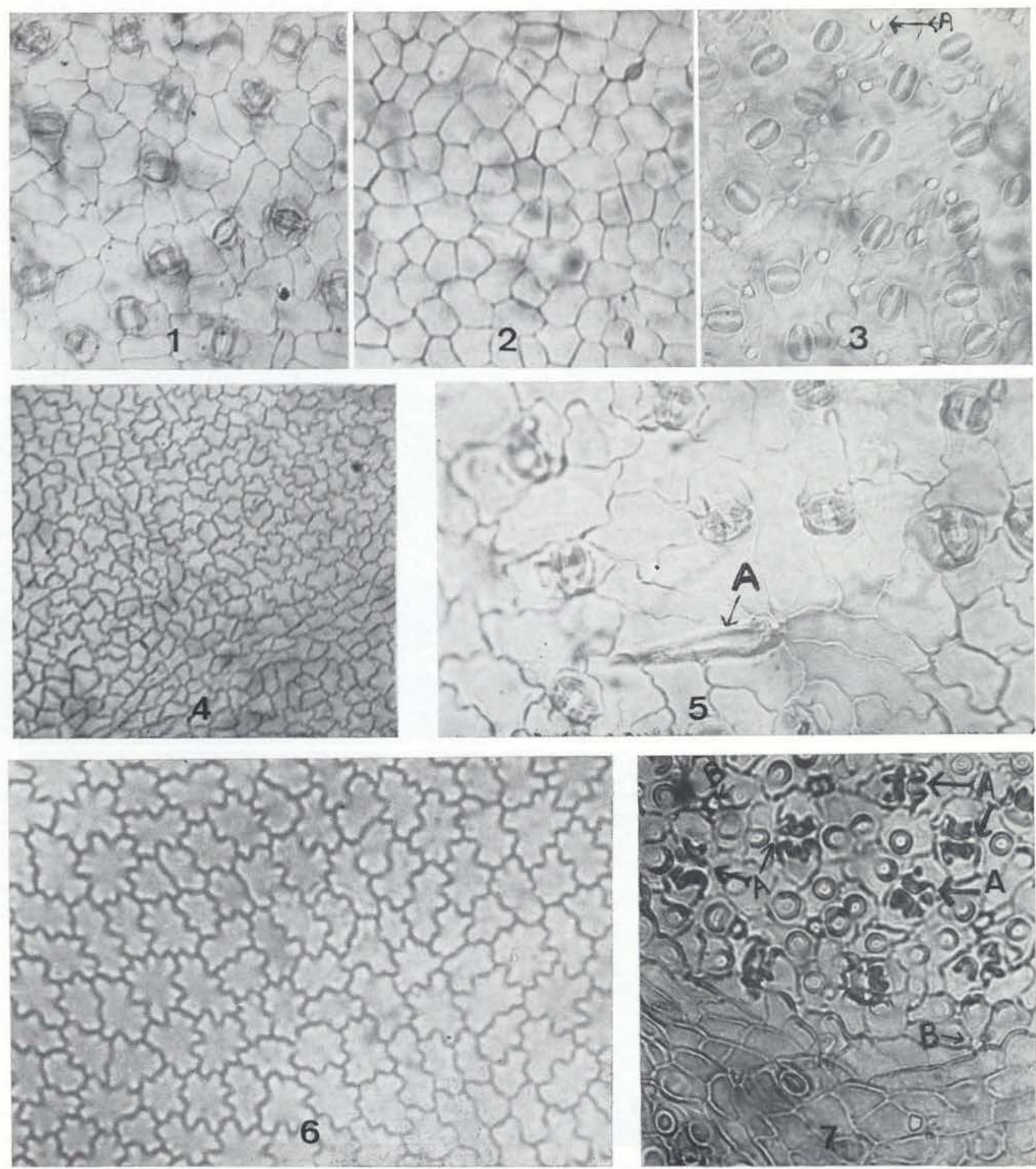

Microfoto 1 - A. terminalis Ducke. Epiderme inferior $(640 \mathrm{X})$. Microfoto 2 - A. terminalis Ducke. Epiderme superior $(640 \mathrm{X})$. Microfoto 3 - A. hostmanniana (Nees) Mez. Epiderme inferior: A pelos (640 X). Microfoto 4 - A. hostmanniana (Nees) Mez. Epiderme superior $(640 \mathrm{X}$ ). Microfoto 5 - A. riparia (Nees) Mez. Epiderme inferior: A) pelos $(960 \mathrm{X})$. Microfoto $6-\mathbf{A}$. riparia (Nees) Mez. Epiderme superior formada por células cuja membrana das faces laterais verticais é sinuosa $(960 \mathrm{X})$. Microfoto 7 - A. fragrans Ducke. Epiderme inferior: A) aparelhos estomáticos cobertos por 2 papilas; B) pelos $(640 \mathrm{X})$. 

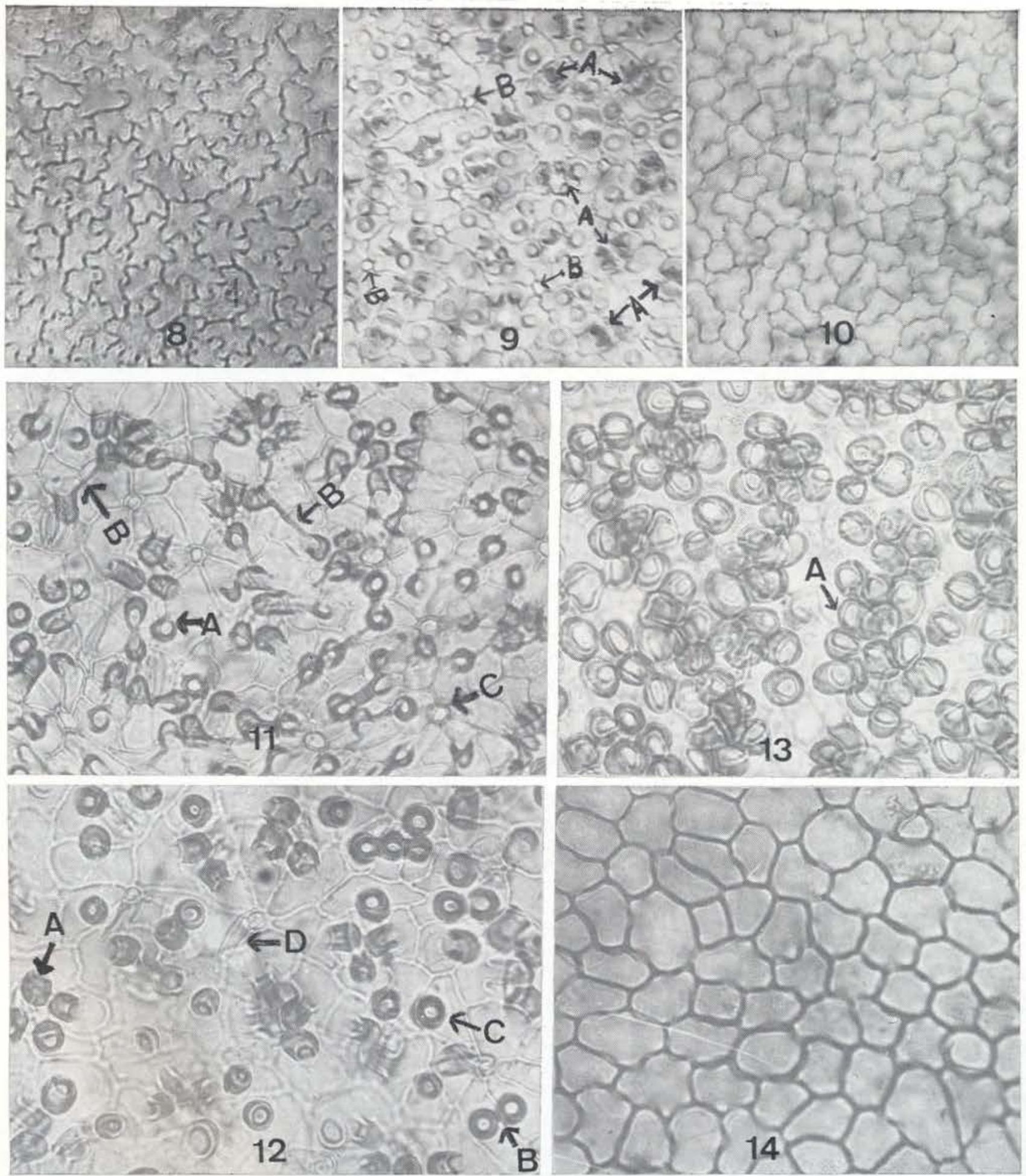

Microfoto 8 - A. fragrans Ducke. Epiderme superior $(640$ X). Microfoto 9 - A. mas Kost, Epiderme inferior: A) aparelhos estomáticos cobertos por 2 papilas; B) pelos $640 \mathrm{X}$ ). Microfoto 10 - A. mas Kost. Epider. me superior $(640 \mathrm{X})$. Microfoto $11-\mathbf{A}$. burchellii Kost. Epiderme inferior: A) papilas; B) camada de cutina interligando as papilas; C) pelos $(960 \mathrm{X}$ ). Microfoto 12 - A. auckei Kost. Epiderme inferior: A) aparelhos estomáticos cobêrtos por 2 a 8 papilas; B) papilas com forma regular circular; C) papilas com forma regular elítica; D) pelos $(960 \mathrm{X})$. Microfoto 13 - A. rosaeodora Ducke. Epiderme inferior: A) aparelhos estomáticos cobertos por 2 a 8 papilas $(960$ X). Microfoto 14 - A. rosaeodora Ducke. Epiderme superior formada por células cuja membrana das faces laterais verticais em geral é reta ou sub-reta $(960 \mathrm{X})$. 

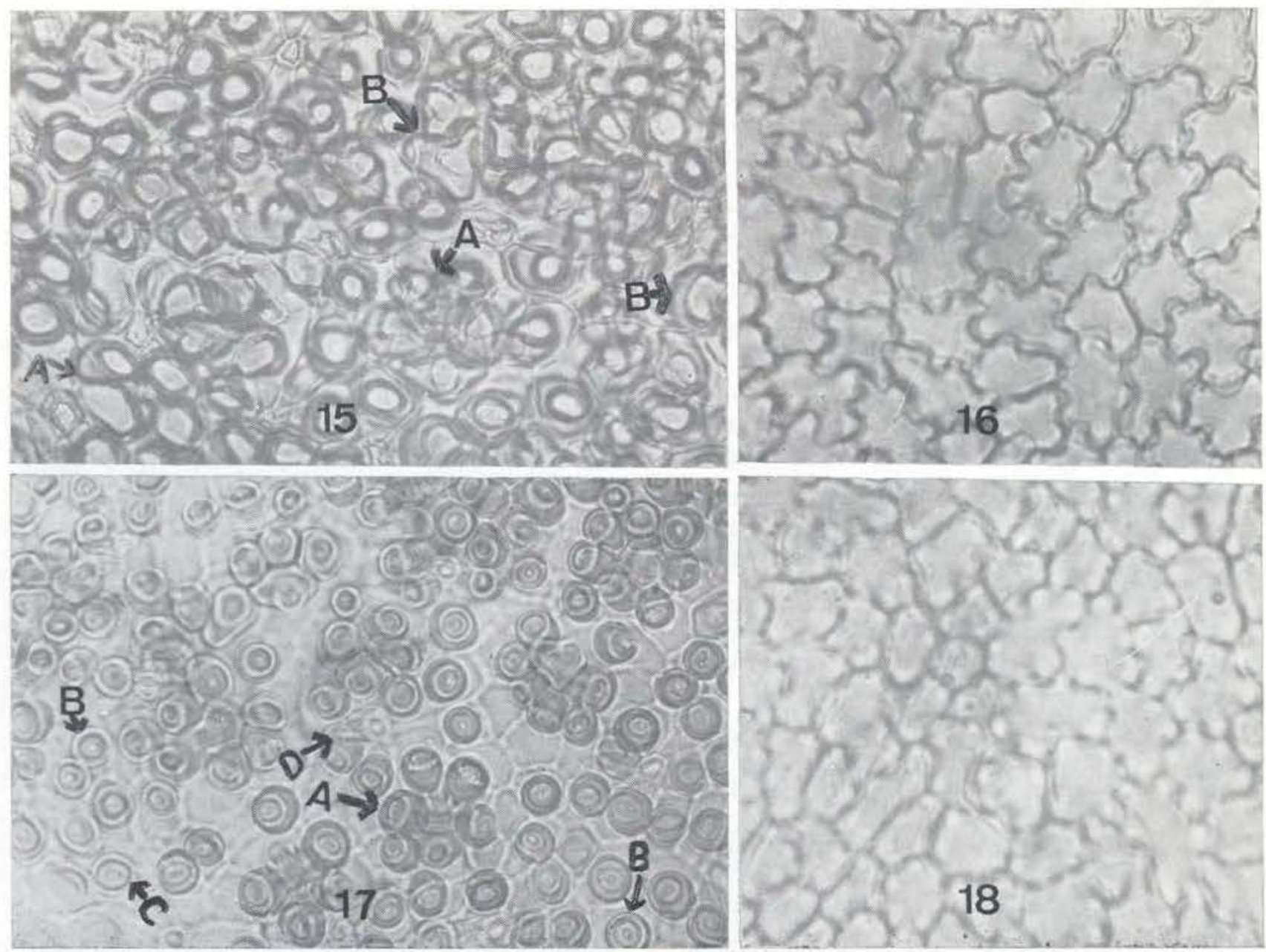

Microfoto 15 - A. permollis (Nees) Mez. Epiderme inferior: A) aparelhos estomáticos cobertos por 2 a 8 papilas; B) papilas adultas com forma irregular $(960 \mathrm{X})$. Microfoto $16-\mathrm{A}$. permoilis (Nees) Mez. Epiderme superior formada por células cuja membrana das faces laterais verticais é sinuosa ( $960 \mathrm{X}$ ). Microfoto 17 - A. parviflora (Meissn.) Mez. Epiderme inferior: A) aparelhos estomáticos cobertos por 2 a 8 papilas; B) papilas com forma regular circular; C) papilas com forma regular elítica; D peios (960 X). Microfoto 18 - A. parviflora (Meissn.) Mez. Epiderme superior formada por células cuja membrana das faces laterais verticais é levemente sinuosa (960 X).

\section{AgRAdECIMENTOS}

O autor agradece ao Conselho Nacional de Desenvolvimento Científico e Tecnológico $(\mathrm{CNPq})$, pela bolsa concedida para que este estudo pudesse ser realizado; ao Dr. William A. Rodrigues e ao INPA por toda atenção dispensada e pela publicação do trabalho.

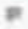

\section{SUMMARY}

In this last paper of a series of 11 , the Author gives a Key for identification of herbarium material of ten known species of rose-wood (Aniba
Aubl,) based on anatomic characters of the upper and lower epidermis of the leaves.

In this summary the key is translated.

\section{KEY FOR IDENTIFICATION OF HERBARIUM PLANT MATERIAL}

1 - Papillae absent in the lower epidermis ... 2 Papillae present in the lower epidermis ... 4

2 - Hairs absent in the lower epidermis; cell walls in general straight or almost straight in both epidermises (microfots. 1 e 2) Aniba terminalis Hairs present in the lower epidermis; character of the cell wall above mentioned occur ring only in the lower epidermis or absent . 3 
3 - Numerous hairs; cell wall in general straight or almost so in the lower epidermis; the upper epidermis with a mixture of straight, almost straight, curved or sinuous cell walls, without predominance of any single type (microfots. 3 e 4) ............... Aniba hostmanniana

Few hairs; cell walls in general slightly sinuous in the lower epidermis and sinuous in the upper epidermis (microfots, 5 e $6 \ldots \ldots$. ........................ Aniba riparia

4 - Stomatal apparatus (stomata) in general covered by 1-2 papillae of the subsidiary cells, in the lower epidermis ............... 5

Stomatal apparatus (stomata) in general covered by $2-8$ papillae, in the lower epidermis 6

5 - Cell wall of the upper epidermis in general sinuous to very sinuous (microfots. 7 e 8 )

Aniba fragrans

Cell wall of the upper epidermis straight, almost straight, curved or slightly sinuous, these forms occurring at the same time, without predominance of any single type (microfots. 9 e 10) ............... Aniba mas

6 - Cutin layer that covers the upper face and enters between the lateral vertical faces of the cells in the lower epidermis appears connecting the papillae (ref. A. burchellii Kost., Rev. Bràsil. Biol. 30(3) 422/423); (microfotc. 11) $\ldots \ldots \ldots \ldots \ldots \ldots \ldots \ldots$ Aniba burchellii Without this character 7

7 - Lower epidermis cells with slender papillae, little developed with a constant regular circular or elliptic form. Diameter of the circular form or the major axis of the elliptical form, in general measuring 3-6 $\mu$ (microfoto. 12) ....................... Aniba duckei Without this character $\ldots \ldots \ldots \ldots \ldots \ldots \ldots 8$

8 - Cell wall of the upper epidermis, in general straight or almost straight (microfots. $13 \mathrm{e}$ 14) ................. Aniba rosaeodora Without this character ................. 9

9 - Lower epidermis cells with papillae measuring in general up to $15 \mu$ in diameter when circular or $15 \mu$ along major axis when elliptic; when adult of irregular shape cells for upper epidermis with sinuous walls (microfots. 15 e 16) ................... Aniba permollis

Papillae of the lower epidermis cells in general not surpassing $9 \mu$ in diameter, usually $6 \mu$ when circular, or $6 \mu$ wide along the major axis when elliptic (the circular and elliptic forms being constant). Upper epidermis cells with slightly sinuous walls (microfots. $17 \mathrm{e}$ 18) ................... Aniba parviflora

\section{BIBLIOGRAFIA CITADA}

Kostermans, A.J.G.H.

1938 - Revision of the Lauraceae. V. A monograph of the genera Beilschmiedia and Aniba. Med. Bot. Mus. Herb. Rijks Univ. Utrecht, 48:866-928.

VATtтMO, I

1968a - Citomorfologia da folha das espécies conhecidas de pau-rosa. I. Estudo do limbo de Aniba rosaeodora Ducke (Lauraceae). Atas Soc. Biol. Rio de Janeiro, 11(6): 207-211

1968b - Citomorfologia da folha das espécies conhecidas de pau-rosa. II. Estudo da epiderme e da nervura central de Aniba rosaeodora Ducke (Lauraceae). Rev. Bras. Biol,, 28(2): 161-165

1968 - Citomorfologia da folha das espécies conhecidas de pau-rosa. III. Estudo do limbo de Aniba parviflora (Meissn.) Mez (Lauraceae). Atas Soc. Biol. Rio de Janeiro, 12(2): 43-46.

1968d - Citomorfologia da folha das espécies conhecidas de pau-rosa. IV. Estudo das epidermes dissociadas e da nervura central de Aniba parviflora (Meissn.) Mez (Lauraceae). Rev. Bras. Biol., 28(4): 427-431.

1969a - Citomorfologia ta folha das espécies conhecidas de pau-rosa. V. Estudo do limbo de Aniba burchellii Kostermans (Lauraceae). Atas Soc. Biol. Rio de Janeiro, 12(4): 181-184

1969b - Citomorfologia da folha das espécies conhecidas de pau-rosa. VI. Estudo do limbo de Aniba duckei Kostermans (Lauraceae). Atas Soc. Biol. Rio de Janeiro, 12(5/6): 257-260.

1969 - Citomorfologia da folha das espécies conhecicias de pau-rosa. VII. Estudo da epiderme e da nervura central de Aniba duckei Kostermans (Lauraceae). Rev. Bras. Biol., 30(3): 103-107.

1970 - Anatomia da folha das espécies conhecidas de pau-rosa. VIII. Citomorfologia das epidermes superior e inferior de Aniba burchellii Kostermans (Lauraceae). Rev. Bras. Biol., 30(3): 419-429.

1972 - Anatomia da folha das espécies conhecidas de pau-rosa. IX. Citomorfologia das epidermes superior e inferior de Aniba terminalis Ducke (Lauraceae). Rev. Bras. Biol., 32(2): 139-176.

1975 - Anatomia da folha das espécies conhecidas de pau-rosa. X. Citomorfologia das epidermes superior e inferior de Aniba permollis (Nees) Mez (Laura. ceae). Acta Amazonica, Manaus, 5(1): 45-50. 